\title{
Initiating a Transdisciplinary Conversation to Improve Indoor Ecologies
}

\author{
Guest Editors: Rachael Wakefield-Rann' and Dena Fam
}

\section{Abstract}

Indoor spaces have not traditionally been considered the domain of human ecology. They have been the subject of cultural, architectural, and sociological inquiry, and more recently the site at which various pathogenic or toxic encounters may be studied; yet, these concerns have rarely been investigated as part of one unified and codependent ecology. This special issue aims to remedy this dislocation by beginning a conversation between a range of disciplinary perspectives concerned with the indoors. This ambition is not only linked to a desire to articulate and connect multiple interacting variables operative in indoor spaces, but also to address both a number of factors that are increasingly creating indoor environmental conditions that are suboptimal for human habitation, and the broader more-thanhuman ecosystems in which they are situated. Although certainly not exhaustive in scope, the research presented in this special issue provides an exemplary profile of situated knowledge that must form the basis of future, integrative, transdisciplinary research into indoor ecologies. Spanning design, architecture, social and human ecology, environmental psychology, sociology, mycology, biotechnology, spatial sciences, statistics, engineering, philosophy, and "lay" and experiential knowledge perspectives, this special issue uncovers a number of the challenges and fertile points of overlap across epistemological approaches and areas of concern within the indoors. The goal of this issue is to highlight the points of divergence, and, more crucially, the points of convergence from which a new transdisciplinary approach to indoor research can emerge.

Keywords: great indoors, human ecology, indoor ecology, knowledge integration, transdisciplinary research

1 Corresponding author: rachael.wakefield-rann@uts.edu.au. 


\section{Introduction: The Indoor Biome}

The earth is comprised of multiple biomes, habitats that support different forms of life and ecosystems. Today, the most rapidly expanding biome on Earth is the indoor environment. As cities and buildings have expanded to cover the globe in both horizontal and vertical space, they have created new habitats for different species and ecosystems to thrive.

It has been estimated that people in many industrialized regions of the world now spend up to $90 \%$ of their lives indoors (Luongo, 2016). As a consequence, it is imperative that an integrated understanding of the composition of indoor environments, what affects them, and how they affect human and ecological health is sought. Yet, very little is known about the indoor ecosystems we inhabit. What is known tends to be confined within disciplinary silos, obfuscating the ways that objects, bodies, structures, and meanings interact and react to create indoor ecologies.

This lack of interaction between different bodies of knowledge is concerning, as research in multiple disciplines is revealing that the confluence of multiple materials in the indoors is central to the creation of suboptimal ecologies. For example, a particular combination of volatile organic compounds emitted from wall paint, antimicrobial chemicals in cleaning products, a dog, and minimal ventilation to ensure temperature control would together produce a very particular indoor biochemical environment that might affect occupants differently if any one of these elements was removed from the system. Consequently, the ways in which indoor environments can cause harm are complex, nonlinear, and relational. As a starting point, one must then recognize that the composition of the indoors depends not only on the entities that reside there, but how they interact and transform over time.

The traditional focus of human ecology has been to tackle complex, "wicked" problems that emerge out of socioecological entanglements (Brown et al., 2010). As Dyball and Newall (2014) proposed, human ecology "has a practical interest in how systems of production, distribution, and consumption might be redesigned, so that the reasonable daily needs of people ... might be met without causing harmful impacts" (p. 7). This interest in moving away from the individualization of responsibility for systemic health and environmental sustainability issues to instead focus on how human needs can be met in less harmful ways will be crucial for improving indoor environments. Despite indoor health being central to the inception of human ecology, a focus on the constitution of indoor ecologies has largely been superseded by a focus on the consequences of everyday actions on more macro socioecological issues and planetary health. When Ellen Richards first proposed the concept of human ecology over 100 years ago as a "knowledge of right living," she explicitly addressed the significance of how we live in our indoor environments, and 
went on to found Home Economics in the United States (US) (Dyball \& Carlsson, 2017). In this special issue we propose a return to the micro and mesoscales of the indoors to ask how we might live well in this expanding biome.

Answering this question in a holistic way requires consideration of a range of perspectives on indoor ecologies, and a transdisciplinary approach to research that seeks to overcome the inherent divide between academic disciplinary knowledge and societal knowledge. While such integrative approaches to research are not mainstream in the academic system and remain an "intellectual, cognitive, communicative, and institutional challenge" (Vilsmaier et al., 2018, p. 170), the call for research that crosses disciplines and links knowledge production to the transformation of complex problems is not new. Influential scholars have addressed the challenge of integrative research over decades (e.g., Freire, 1996; Nicolescu, 2002; Piaget \& Wells, 1972) and have provided the grounding for exploring relational thinking on indoor ecologies in this special issue. In particular, the central concern here regards the importance of presenting in-depth case studies and critical reflection on collaboration and collective learning, which often lack in transdisciplinary research (Fam et al., 2018).

\section{Facilitating Transdisciplinary Interaction in this Special Issue}

In the interest of initiating a much-needed exchange of knowledge to address suboptimal indoor biomes, this special issue sought to bring together scholars across the natural and social sciences to critically assess and learn from one another's work. Knowledge exchange between disciplines can be critically inhibited not only by exclusive information-sharing platforms, such as journals and conferences, but also by disciplinary conventions for presenting research and measuring the validity of data. Critical reflection on what constitutes "valid data" and whose perspective should be valued is a necessary process in transdisciplinary approaches to inquiry. The very term "data" suggests a positivist epistemology and a politics of evidence associated with "reliability and validity" (Denzin, 2013). A solely positivist perspective rejects intuitive and introspective forms of knowledge, such as interpretations of a comment in an interview, a fragment of a field note, or an anecdote (MacLure, 2013). In relation to transdisciplinary approaches to research into complex problems, Palmer et al. (2018) noted that data have also been attributed with an agency outside of a single methodological approach, standard, or method. This is especially evident in data obtained through interviews, in which the voice of an informant can sometimes speak across and beyond disciplinary theories to which it is assigned. In attempting to draw together a range of perspectives on indoor 
ecologies, this special issue includes reference to both qualitative and quantitative data to support the case for transdisciplinarity as a means of improving some of the complex problems emerging in indoor environments.

Transdisciplinary research requires a type of critical reflection in relation to one's own and others' perspectives, values, data, and methodological approaches that inevitably creates challenges. In cases when individuals working within different knowledge systems meet to collectively address an issue, uneven power relations have the potential to emerge. Often, power dynamics come to reflect the dominant modes of knowledge production and marginalization in broader culture; for example, voices of scientists may be elevated above traditional knowledge holders or perspectives based on phenomenological accounts of a situation.

To explicate the transdisciplinary orientation of this special issue, the editors provided authors with detailed guidance for structuring their own contributions and for reviewing alternative disciplinary perspectives. From the outset, the call for papers requested contributions that recognize healthy and sustainable indoor ecosystems as a complex issue. To highlight and begin to transgress disciplinary distinctions, the editors also requested that authors make explicit several elements in their research based on principles of transdisciplinarity. Each author was requested to address the following questions:

- How does your paper offer a contribution to resolving a larger societal problem?

- How is your research participatory or collaborative?

- How does your research transgress disciplinary boundaries?

- How have multiple sources of knowledge from stakeholders and/or disciplinary perspectives sought to be included in your paper?

This protocol was intended to help each author reflect on how their own research might be positioned within knowledge communities beyond their own disciplinary field. In the process, it also provided an opportunity for mutual learning between contributors as well as collaborative research into suboptimal indoor environments. In an attempt to encourage knowledge sharing between contributors, the editors requested lead authors review another manuscript in the special issue from an unfamiliar disciplinary field. This process provided authors with an opportunity to gain insight into alternative perspectives on the problem of indoor ecosystems across fields of inquiry, and ensured that contributions were communicated in language accessible across fields of inquiry. Moreover, this process was instructive in highlighting some of the disciplinary disparities in the framing of indoor environmental health issues, the normative intent of research, the range of methodological approaches adopted, and what constitutes data across fields of inquiry. 
To assist authors in reviewing manuscripts beyond their own disciplinary field and convention, they were provided 12 questions to guide their review. In addition to standard questions around the appropriateness of content and length, questions specific to the overarching goal of the special issue were included:

- Has the author included a description of what interdisciplinarity or transdisciplinarity means in the context of their contribution and how it contributes to theory in practice?

- Have authors sought broad societal outcomes in their contribution to new knowledge?

- Is the language used accessible and engaging to multiple audiences across disciplinary fields?

In reviewing the manuscripts, the editors were also aware of the need to respect disciplinary conventions and avoid elevating any method or format for presenting research above others, provided clarity and accessibility were achieved. As a result, papers appear in the conventional scientific format, with an Introduction, Methods, Results, Discussion, and Conclusion, as well as full provision of data from some contributors, where needed. Additionally, a range of social scientific and designbased conventions were included.

This approach to framing the special issue and guiding authors to contribute reflexive and accessible papers resulted in a rich and diverse array of scholarship. Despite the range of disciplinary foci and epistemological approaches presented, a number of salient shared themes emerged across the papers. An exploration of these themes provides an apt starting point to develop a more integrated and systemic understanding of indoor ecologies and indoor environmental health.

\section{Emerging Themes in Indoor Ecology Research}

The breadth of papers in this special issue reveal four distinct but intimately entangled themes: (1) the psychological, social, and biophysical health effects of living in polluted indoor spaces; (2) the adaptation of living practices and environments in response to urban planning; (3) the significance of both affective and molecular qualities of indoor air; and (4) climate change and emerging forms of vulnerability associated with decreasing indoor environmental quality. Although these themes certainly do not account for the complete array of current indoor environmental health issues, they cover a significant breadth and depth of some of the most pressing contemporary indoor environmental challenges.

The diversity of perspectives represented across the themes elevate a range of human and nonhuman actors not encapsulated by any single viewpoint- that is, creating a more complex and nuanced picture of the more-than-human ecology of indoor 
spaces (Whatmore, 2006). Through these themes, the articles also highlight the interplay between forces acting at micro, meso and macroscales, and the dynamic and potentially reinforcing linkages between them that are determining the composition of indoor environments.

\section{Living in Polluted Indoor Ecosystems}

Indoor environments become polluted through numerous sources both internal and external to the indoor space itself. The types of pollutants that amass indoors vary based on geographical factors; for example, urban indoor spaces generally accumulate more emissions from traffic than rural ones, and the types of fuel used in the home, such as smoke fires, produce high indoor emissions (Luongo, 2016). However, there are a number of concerning trends emerging across industrialized nations associated with the proliferation of certain types of consumer products. Notably, research from North American cities is showing that emission rates of certain air pollutants in personal care products are comparable to that of benzene from motor vehicles throughout the day (Coggon et al., 2018), with similar patterns observed in China (Yang et al., 2018).

Often, sources of indoor pollution are invisible or obscured, and individuals must rely on external authorities and their prescribed forms of measurement and instrumentation to provide knowledge about their living spaces. This dependence on the methods currently employed by authorities to produce and certify the evidence of harm is often problematic, as many emerging indoor air pollutants are either not deemed harmful or not measured until well after they have taken effect, despite affected individuals often noticing their presence (Murphy, 2006; Shapiro, 2015). As a result, scientists and citizens are increasingly calling for greater community involvement in the measurement of pollutants to protect themselves and keep the industries behind the emissions accountable (Pritchard \& Gabrys, 2016; Regalado, 2017). Accordingly, a number of papers in this special issue explore some of the physical and psychological effects of the uncertainty and lack of control associated with indoor pollution.

Pollution of indoor environments not only affects people through molecular interactions between bodies and toxicants, but also profoundly affects one's sense of existential security and mode of being in the world. Through their qualitative research with residents living in contaminated urban sites across Australia, Connon et al.'s (this issue) paper provides compelling evidence of the extent to which a contaminated home can affect not only the bodies of individuals, but perceptions of security normally associated with home environments. In these cases, a sense of control over one's future is often replaced with "feelings of isolation, threat, insecurity and a sense of powerlessness." Through their attentiveness to the spatial dynamics 
of experiences of contamination, the paper reveals that participants altered their practices in numerous subtle yet significant ways to avoid the risk of contamination, some of which included stopping growing vegetables in their gardens, keeping their windows closed, and either stopping using tap water or boiling it for washing dishes, food preparation, and personal care.

Aligned to Connon et al., Wakefield-Rann et al.'s (this issue) paper also demonstrates how individuals change their practices in response to perceived indoor environmental health hazards to protect themselves and their families. Drawing on theories of social practice, this paper presents findings from a qualitative investigation of parents' attempts to create a safe and hygienic home environment for their children. The practices carried out by Sydney parents with children under the age of five reflects a deep sense of uncertainty about what types of household chemicals and "germs" represent the greatest risk to their families. The burden of responsibility for managing families' chemical "body burdens" (Mackendrick, 2014) and pathogenic exposures is compounded by the demands of other household practices that compete for time and, in most cases, fall to mothers to negotiate expediently.

Both Connon et al.'s and Wakefield-Rann et al.'s papers highlight the uncertainty that permeates the landscape of risk within home environments causes significant anxiety, and adds additional cognitive and psychological burdens to everyday life. Also central to both papers is the erosion of agency and control of those dwelling in particular indoor environments. In the case of Connon et al.'s paper, the indoor environments of residents' homes are subject to a history of land-use practices with toxic legacies, as well as the political and corporate will to remediate land. Similarly, the participants in Wakefield-Rann et al.'s paper are limited to acts of "precautionary consumption" (Mackendrick, 2015) to remove toxicants from their homes in the absence of sufficient precautionary regulation against harmful classes of chemicals.

Although the primary attention in these papers is to issues of disempowerment and the inability to control the environment in which one lives, this is not to say the research participants do not exercise agency and strategically adapt their lifestyle practices around the issues they confront. The ways in which individuals and groups make micro-adaptations in the face of systemic forces over which they have limited control is also central to the following theme of urban planning and adaptation.

\section{Urban Planning and Adaptive Indoor Lifestyle Practices}

The influence of broad urban landscape transformations on changes in indoor practices and environmental exposures is central to a number of articles in this special issue. As the global population increases and the middle classes grow, urban areas around the world are rapidly expanding and densifying (Desai \& Kharas, 2017). The types of agents, priorities, values, and power dynamics that are guiding urban planning are determining, in large part, the form and constitution of indoor environments. 
For example, governments and planners influence indoor environments through decisions about vegetation cover, which consequently influences urban biodiversity, temperatures, perceived requirements for air-conditioning, and the types of allergens in the air (Douglas et al., this issue; Mellick Lopes et al., this issue; Stokols, this issue). They also guide decisions about where certain polluting industries can be situated, and subsequent decisions over whether to build residential dwellings on that land (Connon et al., this issue).

Central to questions of urban planning are considerations of who cities and regions are designed for. The way that different types of knowledge, experience, and data are captured and deemed valid plays a key role in shaping landscapes. Communities whose needs have not been considered in such designs must consequently adapt their lifestyle practices onto the structures they have been provided, often resulting in further marginalization (Dooling \& Simon, 2012). Scholars such as Whatmore (2006), Franklin (2017), and Maller (2018) have argued that the framing of healthy urban areas in human-centric terms has had detrimental effects not only on the other organisms that occupy cities, but also the humans that rely on their "ecosystem services," such as cooling and clean water from increased vegetation cover. In turn, they advocate for a conceptualization of healthy urban environments as more-thanhuman in research and policy, and for the importance of transcending disciplinary boundaries to achieve this. Similarly, the articles in this special issue highlight the often subtle transformations that are occurring to dominant styles of dwelling in the modern world that may have been overlooked, but have a profound effect on everyday lives.

In his paper, Stokols presents a broad macropolitical and cultural context currently shaping indoor life in industrialized societies. In doing this, he prompts us to recognize the profound influence of the proliferation of cyber technologies, particularly since the 1980s, on the form and functioning of indoor ecosystems, as well as the urban environments that shape them. He notes that the spatial, temporal, and organizational boundaries associated with residential, educational, occupational, recreational, and commercial settings have become increasingly blurred. In this way, digital communications and virtual communities have since interwoven and coevolved with individuals' place-based environments. With reference to concepts from environmental psychology, Stokols explores how this shift has meant homes are no longer just a refuge from work and a space for family life. Rather, they function as electronic hubs and places where work and a multitude of entertainment options have intruded, or, as Stokols put it, "indoor environments have become increasingly polyfunctional, as their boundaries have been rendered more permeable and fluid by cyber technologies." The changing purposes of indoor environments are exerting pressure on the shape of cities, as cafes and homes become multifunctional offices, and the needs for convenient access to bank branches decreases as more transactions become digital. Similarly, changing use requirements for the indoors alter our 
expectations about the level of comfort and other amenities that are provided to enable us to reside inside for prolonged periods of time. Importantly, these additional amenities also often come at a significant cost in terms of the material and energy required to manufacture and run them.

The role of city planning in the ways individuals attempt to create comfortable, protective, and livable home environments is also at the center of Mellick Lopes et al.'s (this issue) paper. The authors note that "[a]s the climate warms, indoor environments facilitated by technical infrastructures of cooling are fast becoming the condition around which urban life is shaped." These factors are compounded by rapidly densifying suburbs, based around a model of urban living that promotes lifestyles carried out in discreet, climate-controlled atmospheres. The promise of air-conditioned indoor spaces has guided city planning and enabled other means of cooling the urban environment, such as increased vegetation cover and free water, to be deprioritized. The negative effects of these decisions are disproportionately experienced by those already economically marginalized, who cannot afford airconditioning, and do not have the capacity to modify their home environments for cooling due either to poor design or because they do not own their property. These residents adopt practices of "thermal rationing" to balance the competing pressures of comfort and financial sustainability.

A similar set of pressures was felt in the community of the New Ngelepen dome settlement discussed by Yuliar et al. (this issue). Here, people were forcibly displaced by an earthquake near Yogyakarta, Indonesia, and relocated to a purpose-built community of "dome" houses in a style pioneered by the international Domes for the World group. Through their analysis of the settlement grounded in actor-network theory, the authors detail a significant clash between assumptions about interior and exterior lifestyle practices embedded in the building designs and traditional lifestyles, forcing residents to retrofit their domes and adapt their practices.

The analysis presented traces the implications of developing structures that do not respect traditional ways of living and interacting between the indoors and outdoors. The omission of a tritisan, an outdoor shelter from sun and rain, and a back doorway from the dome designs meant that important outdoor activities, such as plant cultivation and sheep breeding, which are demarcated and isolated from indoor activates, could not be maintained in a culturally appropriate way. The authors' analysis also reveals that by valuing some actors and uses of space over others in the planning process, many residents' experiences of being in the broader community were diminished. For example, decisions to paint the domes white to reflect sun and keep the indoors cool meant that a large amount of glare was generated, as the close proximity of the buildings and lack of other colors or ornamentations on their white surfaces were not taken into account. 
The implications of the values that are embedded in the form of buildings and indoor environments are further borne out in Lee and Wakefield-Rann's (this issue) paper, which examines subtle shifts in how people engage with risk according to archetypal modern apartment lifestyles. With reference to the philosopher Peter Sloterdijk (2016), they examine how from the comfort of an apartment one can achieve daily "resocialization and attainment of worldliness" through a choice of media, and control over the content and dosage of "reality influx" one wishes to absorb. An indoor apartment space allows for content from around the world to enter the apartment cell through various media, while still insulating and providing "immunity," comfort, and distance. As Sloterdijk (2016) argued, this mode of engaging with the world can create a state in which vast quantities of information about potential risks are communicated, which can elicit a type of psychocultural "autoimmune" response. This response may include mental stress that, if not adequately managed, has the potential for adverse effects on individual mental health and the politic as a whole.

In addition to their affective consequences, urban planning decisions also play an important role in the types of pollutants or other health-affecting particulates to which people are exposed indoors. The participants in Connon et al.'s (this issue) study of residents' responses to remediation of the contaminated land on which their homes sit links directly to the ways in which governments and planning authorities have historically restricted or allowed the use and disposal of certain contaminants on land and in water, the way the remediation technologies are selected and residents are engaged in the process (or not), and increasing demand for housing in rapidly densifying urban areas. These combined factors have led to a situation in which residents do not feel safe in their own homes.

Similarly, Wakefield-Rann et al. (this issue) discuss how decisions made by regulators and product manufacturers about the amount and types of chemicals that are allowed in consumer products contribute to both the levels of anxiety that parents feel in relation to their homes, and the actual degree of hazardous material to which they are exposed. Exposure to pollutants in the home is exacerbated by numerous factors that are encouraging people to spend more time indoors. As Stokols suggested, increased digital connectivity and the blurring of work and home spaces are encouraging people in many places to spend more time at home than ever before. Mellick Lopes et al. (this issue) also alerted us to the effects of cities that are designed around infrastructures of cooling that encourage people to spend time in climate-controlled indoor environments, rather than attempting to improve the outdoor thermal amenity.

The geography and design of cities is central to Douglas et al.'s (this issue) paper, which reports on the most comprehensive mapping of the spatial and temporal patterns of aeromycota (airborne fungi) across urban Sydney to date. Their approach of using geographic information system mapping techniques to predict the concentration and 
diversity of airborne fungi enables the relationships between building design, urban design, changing climate variables, and fungi exposure levels to be observed. The health effects of inhaled fungal particles can include exacerbation of asthma, allergic rhinitis or sinusitis, hypersensitivity pneumonitis, allergic respiratory ailments, and atopic dermatitis, depending on individual sensitivities and the differing pathogenic properties of the fungi. In drawing out both spatial and other variables that affect the distribution of aeromycota, Douglas et al. demonstrate how the exclusion of certain parameters in city planning can result in certain indoor (and other) health issues being exacerbated. How, and to what extent, indoor air is deemed unhealthy relates to the next theme, which examines more closely how properties of indoor air are defined, understood, and measured.

\section{The Physical and Affective Properties of Indoor Air}

Murphy (2006) in her text Sick Building Syndrome discussed how the design of office spaces and heating, ventilation, and air-conditioning (HVAC) systems have been informed by definitions of health and harm determined in relation to a narrow set of comfort indicators, such as temperature and humidity, for adult, white, male bodies. These indications and their materialization in office building design have established what she has termed a "regime of perceptibility," which has disabled our capacity to see and measure how different bodies are affected by different elements of the indoor environment, such as chemicals off-gassing from paints and carpets. Murphy and other researchers such as Hoffman (2017) and Wylie et al. (2017) contended that the way we define and measure the properties of air need to be challenged to account for that all potential hazards to all potential bodies.

Mellick Lopes et al. (this issue) remind us that what we now understand as "airconditioning" refers only to one way of "conditioning" the air based on a particular set of values. They highlight the public health debates in the early twentieth century in which approaches advocating for the circulation of "fresh air" in buildings were pitted against those arguing for the value of climate-control technologies that heated or cooled recirculated air. Like many aspects of home design, the features that are considered essential for human health at particular times directly reflect the way society understands the body, disease and its transmission, and living well, more broadly. For example, as "germ theory" gained cultural traction in Europe, bathrooms and kitchens transformed from being heavily ornamented, multicolored, fabric-adorned spaces, to white, hard, enameled surfaces that could reveal any germcarrying dirt that may be present (Lupton \& Miller, 1996).

Central to twentieth- and twenty-first-century air-conditioning, and design for the indoors more generally, is the emergence of comfort as an important guiding criterion. Shove (2003) argued in her seminal text Comfort, Cleanliness and Convenience that like cleanliness, standards of comfort have escalated and become standardized across much of the industrialized world. Mellick Lopes et al. alert 
us to the consequences of creating cities in which the indoors is characterized by air-conditioning by emphasizing the implications for energy consumption and on bodies. They contend that air-conditioning is not only further contributing to the warming of the climate, but also creating bodies that are more "sedentary and passive," as they no longer have to work to adjust and acclimatize in a state of air conditioned "thermal monotony" (Mellick Lopes et al., this issue).

Aside from its direct effects on the thermal comfort of occupants, the way indoor air is conditioned also determines what organisms it carries. Douglas et al. (this issue) sensitize us to the crucial relationship between the concentration and composition of indoor bioaerosols (microscopic organisms in the air), and building ventilation types (natural, mechanical, or mixed). The authors note that the interaction between these variables is largely influenced by temporal changes in the inflow of outdoor air, and ventilation requirements associated with thermal conditioning or other indoor environmental quality requirements.

Douglas et al. also highlight that only some aspects of air, such as certain chemical air pollutants and pollens, have been mapped for distribution and diversity in urban settings. Their research into aeromycota mapping adds another layer of insight to our understanding of urban air, which has been largely obscured. By articulating this additional dimension of air through the use of mapping techniques that encapsulate spatial and temporal variables, buildings and their ventilation systems can begin to be designed more appropriately for the requirements of the urban landscape in which they are situated. This addition of aeromycota to air mapping also has potentially significant implications for assisting individuals with self-management of allergies. If provided with readily available information (such as weather data) and an easy way to comprehend their own building ventilation systems, sensitive individuals could limit their exposure.

Aside from the intentional conditioning of indoor air for desirable qualities, such as temperature and freshness, the role of air as a vector of potential hazards was a prominent theme throughout the articles in this issue. Wakefield-Rann et al. (this issue) highlight how the way we are trained to see hazard, or the "regime of perceptibility" we inhabit, determines how we clean our home environments. Normative cleaning regimes were revealed in this paper to be guided by a set of sensory cues and culturally entrained habitual practices that disproportionately sensitize participants to the presence of "germs" over other hazards, such as aerosolized chemicals in cleaning products. The irony of this limiting conception of "clean" and "healthful" indoor atmospheres as germ free is that we add synthetic imitations of cleanliness and freshness in the form of "air fresheners," which are known to contain some of the most hazardous chemicals used in indoor environments (Steinemann et al., 2017). 
Lee and Wakefield-Rann's paper provides an important context for the evolution of phenomenological and technoscientific understandings of what air is and how it is experienced in the broadly Western cannon of thought. With reference to Sloterdijk's (2016) contention that air cannot be adequately understood without highlighting the technical changes inflicted on the atmosphere over the course of the last 200 years, readers are provided insight into some of the sociopolitical arrangements that have made certain properties of air culturally and scientifically explicit, and of concern. Sloterdijk (2016) traced developments in "atmospheric terrorism" from the initial uses of gas warfare in World War I, through the industrial-scale extermination camps used in World War II, to gas chambers used sporadically in the US, and radioactive matter atmospherically experienced through nuclear power. These developments, he proposed, have resulted in a "reordering of 'environmental' awareness towards the invisible milieu of waves and rays" (Sloterdijk, 2016, p. 130). Similarly, Sloterdijk (2016) demonstrated how the understanding of air that underpins "atmotechnics" have provided the air-conditioning technology and associated practices that increasingly shape public and private spaces of the twenty-first century. He suggested that various air-conditioning and climate-control technologies have both enabled and testify to the cultural preference for the indoors, in that spaces where identity is constructed and life's activities are carried out-what Sloterdijk (2016) termed "addiction to dwelling" (pp. 169-170)—subsequently extend beyond home to working, shopping, and spectating (i.e., sports and cinema), among other doings.

The negative effects of landscapes shaped according to a preference for comfortable indoor activities are most acutely felt by vulnerable populations. As discussed in the Urban Planning and Adaptive Indoor Lifestyle Practices section above, Mellick Lopes et al. (this issue) detailed how the amplification of "infrastructures of cooling," particularly under a warming climate, have the greatest effect on communities without the means or capacity to access air-conditioning. The following section examines the relationship between climate change, indoor environments, and vulnerability in more detail.

\section{Climate Change and Emerging Forms of Vulnerability}

Many of the forms of vulnerability and harm to humans and the environment included in this special issue have been discussed in the literature under the term "slow disaster," as they lack the spectacular, immediate, and explosive qualities that are typically associated with "typical" disasters (Joyner \& Orgera, 2013; Morrison, 2017). However, Nixon (2011) and others (O'Lear, 2016) made the persuasive argument that where deliberate actions are taken that have known effects on human health or the environment, such as emitting large quantities of greenhouse gases 
or using chemicals that are persistent or bioaccumulative, "violence" is a more appropriate term than "disaster." Note here, Nixon (2011) characterized slow violence as "a violence that occurs gradually and out of sight, a violence of delayed destruction that is dispersed across time and space, an attritional violence that is typically not viewed as violence at all" (p. 2). The papers under this theme in the special issue show how the slow violence of climate change is affecting the evolution of indoor lifestyles in two key ways: first, to maintain comfort and safety in response to new thermal and climatic conditions, and, second, to reduce the effect buildings and lifestyle practices have on the environment.

Douglas et al. (this issue) reported that high average temperatures and high relative humidity favor microbiological growth, therefore, exacerbating urban bioaerosol proliferation, and, consequently, the vulnerability of those who experience allergies. At a far greater scale, Stokols reminds us that nearly half the world's population lives within $150 \mathrm{~km}$ (93 mi) of a coast and upwards of 200 million people reside near shorelines, the majority of which will be forced to endure involuntary migration caused by extreme weather events, depriving them of the physical and existential security offered by the indoors. Increased forced migration also raises questions about how people will be resettled and new indoor environments created, according to the physical, cultural, and economic needs of displaced populations.

Although not a climatic event, Yuliar et al.'s (this issue) study of post-earthquake community resettlement in Yogyakarta, Indonesia, provided an instructive example and cautionary tale of the implications of how indoor lifestyle needs and practices are considered in post-disaster resettlement. The particular agents that were engaged to contribute to the design of the new settlement intended to house displaced communities precipitated the creation of indoor and exterior spaces that failed to meet the needs of residents. The discussions between architects, funding bodies, and local government officials highlighted competing design priorities, with the desire for buildings that not only "respond to the physical environment," but also to the cultural needs and aesthetics of the community. The structures that emerged did not meet community needs in several important ways, requiring residents to retrofit, and ultimately abandon, previous aspects of their lifestyles. The politics around how settlements for displaced populations are structured for the perceived physical, cultural, and aesthetic needs of communities has endured in urban studies and geography since at least the 1950s (see Young \& Wilmott, 1957; Zukin, 2009). However, this debate will take on new and potentially more urgent dimensions, as forced migration due to extreme climatic events increases. In this context, the tensions between the ways communities value and use indoor spaces, and the preferences of international engineers and architects could become more common. This example also reemphasizes the necessity of transdisciplinary approaches to research and intervention, which does not prioritize technical and scientific ways of knowing over traditional, or place-based, knowledge. 
Simultaneously, ways of living indoors are changing in an attempt to reduce the emissions they also produce. Stokols notes that built environments generate a disproportionately high percentage of carbon emissions worldwide. Indoor ecosystems will consequently be challenged to adapt to prevent the exacerbation of climate change by adopting renewable materials and energy, and reducing resource consumption. As Mellick Lopes et al. (this issue) demonstrate, some individuals and communities have more constraints imposed by urban design and economic position to improve their own levels of thermal comfort or retrofit their dwellings to reduce their contribution to greenhouse gas emissions.

In cases when individuals and communities have been empowered to adapt their dwellings to enable low carbon lifestyles, one unforeseen consequence has been the alteration of the chemical and microbial environments within buildings. The sealing of doors and windows to reduce indoor-outdoor airflow and consequent energy loss can have the effect of trapping hazardous chemicals and pollutants indoors, as well as reducing the flow of outdoor microbes indoors; both of which are linked to a range of health conditions (Hamilton et al., 2015; Wakefield-Rann et al., 2018). A narrow framing of the desirable attributes of air around carbon can, therefore, mean that other crucial factors that affect human health and the environment have not only been excluded, but also exacerbated by their omission.

Importantly, the papers in this special issue have highlighted many of the ways that people become vulnerable as a result of the composition of, and forces acting on, indoor environments: Yuliar et al. illustrate how individuals can be forced to change their indoor lifestyle practices in undesirable ways if resettlement housing does not meet their cultural and physical needs, while Connon et al. show us how disempowering the contamination of one's home with hazardous pollutants can be, and how disruptions to supposedly safe and protective home spaces affect one's sense of being and security in the world. Similarly, Wakefield-Rann et al. demonstrate how the uncertainty that surrounds pathogens and toxicants in the home environment causes anxiety in parents and leads to maladaptive practices, which often make individuals more vulnerable to harmful exposures. In all of these cases, the ways in which indoor environmental health has been framed have influenced the actions that have, or have not, been taken. The following section draws on the different ways that papers in this special issue have understood the role of spatial arrangements, and metaphors in constructing indoor environments and certain modes of being within them. 


\section{A New Spatial Philosophy for Indoor Ecological Research}

One of the most potentially transformative offerings from the papers in this special issue is an indication of how the psychological, cultural, and scientific conceptualizations of the indoor spaces in which we dwell shape both culture and broader ecological systems. Both Stokols, and Lee and Wakefield-Rann offer compelling characterizations of the implications of co-isolated living in modern societies, which are simultaneously hyperconnected and insulated. The metaphorical characterization of these connected yet isolated indoor worlds has been described respectively by Stokols as "cocoons," and by Lee and WakefieldRann (through Sloterdijk, 2016) as "foams." The analysis offered in both papers explores how one's relationship to dwelling mediates their relationships with the rest of the world. As Stokols notes, the way that digitized homes permit individuals to conduct all manner of activities from inside-from ordering groceries, to working, banking, studying, receiving news updates, engaging with friends, and consuming entertainment-encourages a form of residential cocooning. Stokols aptly characterizes these spaces as "real-virtual mesosystems," in which connections between a particular physical space, and the virtual places accessed from there, meet. He argues that this restructuring of indoor settings and our increased access to, and control over, the information one receives has altered the very fabric of society and daily life.

Lee and Wakefield-Rann trace a similar set of connections, with reference to Sloterdijk's (2016) analysis of the key advent of the telephone for indoor life, which he proposed offered a two-way channel of connecting the apartment dweller linking the domestic interior with the "real" world outside, putting each into a "state of simultaneity" (p. 555) with the other. Essentially, he argued that modern apartment lifestyles, initially supported by the telephone, represent a significant shift from how communication was conducted within the home in the premodern era, where most interactions related to the immediate locality were generally private and with family, and where the sender of all interesting messages beyond these confines was God.

These insights into the transformation of indoor living experiences through telecommunication and cyber technologies is extended by Connon et al., who demonstrate how this spatial and conceptual alteration of dwelling is also changing our relationship with risk. Connon et al. employ the notion of "lifescape" to explore this intersection between individual psychological, physical, and socioeconomic states with the specific material and social environmental contexts in which they operate. Through their findings, they emphasize how the indoor environment is associated with a sense of personal control, as it provides a secure base for identity construction and freedom from public surveillance. Additionally, they stress the 
cultural significance of having a home in particular societies, and the form of existential security and "grounding" this brings, particularly in places with histories of colonialism.

These conceptualizations of space and dwelling, in terms of both what is and ought to be, have implications for how transdisciplinary research is conducted into the future, as the framing of a problem informs the conceptual frameworks and methodological approaches used to understand scientific and societal problems. In this case, framing not only refers to literal descriptions of problems, but also the metaphors we invoke to understand them. For example, Lee and Wakefield-Rann draw on Sloterdijk to demonstrate the power of spatial metaphors by contrasting a conception of our society as a "network" that brings to mind linear connections between nodes in simple geometric space, or as a "foam," which describes the architectural and social situation of simultaneous enclosure and spatial extension. The authors propose Sloterdijk's psychologically and architecturally informed interpretation of human psychosocial space as foam may allow for an account of the complex interweaving of physical and psychic space, which other spatial metaphors may not.

\section{Moving Forward}

The rapid growth of the indoor biome is a result of unprecedented material and atmospheric habitat engineering by humans, based on our perceived needs and desires. The papers in this special issue have demonstrated that, in addition to providing shelter and comfort, indoor environments can represent atmospheres permeated by hazard and insecurity for when human needs are miscalculated or inadequately provided for.

This special issue has started a conversation about what is, and ought to be, noticed, measured, and valued in indoor environments from different perspectives, including design, architecture, social ecology, environmental psychology, sociology, mycology, biotechnology, spatial sciences, statistics, engineering, philosophy, and lay or experiential viewpoints. In highlighting these diverse perspectives, values, and ways of knowing, the cases presented in this issue demonstrate how certain forms of action are made possible, or obfuscated, depending on how a problem is defined, and where the surrounding boundaries are drawn. By bringing these diverse perspectives into conversation with one another, such margins of mutual understanding can begin to expand and become adequately nuanced to guide action across multiple social scales.

The exchange across heterogenous and often disparate and disconnected disciplinary fields facilitated by this special issue has also drawn attention to an array of essential nonhuman participants in the construction and experience of the indoors as morethan-human environments. Some important nonhumans that exert agency in indoor 
ecologies include the air (as carrier of microbes, fungus, chemical toxicants, and heat, among other qualities), chemical toxicants (in consumer products and contaminated land and air), microbial and fungal life, natural disasters (e.g., earthquakes and climatic events), buildings and urban environments (such as homes, offices, and suburbs), furniture and other indoor products, and contaminated soil and water, among many others.

In addition to articulating some of the diversity of more-than-human indoor worlds, this special issue has provided insights into the challenges and value of transdisciplinary research and collaboration. The articles included represent often profoundly divergent epistemological approaches to research, yet many points of convergence could easily be found when presented together under the overarching theme of indoor environments. In addition, the research in the special issue traverses a range of cultural and geographic contexts across scales, from micro-interactions in the home, to macroclimatic events that affect all organisms and ecosystems.

By elevating the perspectives and experiences of those affected by the decisionmaking that shapes indoor ecosystems, the articles in this special issue have begun to give voice to some of the humans, and nonhumans, that have previously been excluded from planning, design, and research. This special issue has established a dialogue upon which researchers across disciplines can continue to reflexively build a shared language and shared understandings of the multiple actors, interests, and livelihoods at stake in indoor environments. More importantly, this special issue represents a necessary first step for a transdisciplinary collaboration between researchers, policy-makers, and communities to begin to transform "the great indoors" into a biome that can sustain life into the future.

\section{References}

Brown, V. A., Harris, J. A., \& Russell, J. Y. (Eds.). (2010). Tackling wicked problems through the transdisciplinary imagination. London, UK: Earthscan.

Coggon, M. M., McDonald, B. C., Vlasenko, A., Veres, P. R., Bernard, F., Koss, A. R., ... de Gouw, J. A. (2018). Diurnal variability and emission pattern of decamethylcyclopentasiloxane (D5) from the application of personal care products in two North American cities. Environmental Science \& Technology, 52(10), 5610-5618. doi.org/10.1021/acs.est.8b00506

Denzin, N. K. (2013). The death of data? Cultural Studies $\leftrightarrow$ Critical Methodologies, 13(4), 353-356. doi.org/10.1177/1532708613487882

Desai, R. M., \& Kharas, H. (2017, July 13). Is a growing middle class good for the poor? Social policy in a time of globalization. Brookings. Retrieved from www.brookings. edu/research/is-a-growing-middle-class-good-for-the-poor-social-policy-in-a-time-ofglobalization/ 
Dooling, S., \& Simon, G. (Eds.). (2012). Cities, nature and development: The politics and production of urban vulnerabilities. In S. Dooling \& G. Simon (Eds.), Cities, nature and development (pp. 3-23). Surrey, UK: Ashgate.

Dyball, R., \& Carlsson, L. (2017). Ellen swallow Richards: Mother of human ecology? Human Ecology Review, 23(2), 17-29. doi.org/10.22459/HER.23.02.2017.03

Dyball, R., \& Newell, B. (2014). Understanding human ecology: A systems approach to sustainability. London, UK: Routledge.

Fam, D., Neuhauser, L., \& Gibbs, P. (Eds.). (2018). Transdisciplinary theory, practice and education: The art of collaborative research and collective learning. New York, NY: Springer.

Franklin, A. (2017). The more-than-human city. The Sociological Review, 65(2), 202-217. doi.org/10.1111/1467-954X.12396

Freire, P. (1996). Pedagogy of the oppressed (revised ed.). New York, NY: Continuum.

Hamilton, I., Milner, J., Chalabi, Z., Das, P., Jones, B., \& Shrubsole, C., ... Wilkinson, P. (2015). Health effects of home energy efficiency interventions in England: A modelling study. BMJ Open, 5(4), e007298. doi.org/10.1136/bmjopen-2014-007298

Hoffman, K., Butt, C. M., Webster, T. F., Preston, E. V., Hammel, S. C., Makey, C., ... Meeker, J. D. (2017). Temporal trends in exposure to organophosphate flame retardants in the United States. Environmental Science \& Technology Letters, 4(3), 112-118. doi.org/ 10.1021/acs.estlett.6b00475

Joyner, T. A., \& Orgera, R. (2013). Climate change hazard mitigation and disaster policy in south Louisiana: Planning and preparing for a "slow disaster". Risk, Hazards \& Crisis in Public Policy, 4(3), 198-214. doi.org/10.1002/rhc3.12034

Luongo, J. C. (2016). Towards defining healthy buildings: Investigating the effect of building characteristics and interventions on indoor air microbial exposures and energy efficiency (PhD thesis). University of Colorado at Boulder, CO. Retrieved from scholar.colorado. edu/mcen_gradetds/120

Lupton, E., \& Miller, J. A. (1996). Bathroom, the kitchen, and the aesthetics of waste: A process of elimination. New York, NY: Princeton Architectural Press.

Mackendrick, N. (2014). More work for mother: Chemical body burdens as a maternal responsibility. Gender \& Society, 28(5), 705-728. doi.org/10.1177/0891243214529842

Mackendrick, N. (2015). Protecting ourselves from chemicals: a study of gender and precautionary consumption. In D. N. Scott (Ed.), Our chemical selves: Gender, toxics, and environmental health (pp. 58-77). Vancouver, Canada: UBC Press.

MacLure, M. (2013). The wonder of data. Cultural Studies $\leftrightarrow$ Critical Methodologies, 13(4), 228-232. doi.org/10.1177/1532708613487863

Maller, C. (2018). Healthy urban environments: More-than-human theories. Abingdon, UK: Routledge. 
Morrison, K. (2017). The role of traditional knowledge to frame understanding of migration as adaptation to the "slow disaster" of sea level rise in the South Pacific. In K. SudmeierRieux, M. Fernández, I. Penna, M. Jaboyedoff, \& J. Gaillard (Eds.), Identifying emerging issues in disaster risk reduction, migration, climate change and sustainable development (pp. 249-266). Cham, Switzerland: Springer.

Murphy, M. (2006). Sick building syndrome and the problem of uncertainty: Environmental politics, technoscience, and women workers. Durham, NC: Duke University Press.

Nicolescu, B. (2002). Manifesto of transdisciplinarity (K. C. Voss, Trans.). New York, NY: Suny Press.

Nixon, R. (2011). Slow violence and the environmentalism of the poor. Cambridge, MA: Harvard University Press.

O'Lear, S. (2016). Climate science and slow violence: A view from political geography and STS on mobilizing technoscientific ontologies of climate change. Political Geography, 52, 4-13. doi.org/10.1016/j.polgeo.2015.01.004

Palmer, J., Fam, D., Smith, T. E., \& Kent, J. (2018). Where's the data? Using data convincingly in transdisciplinary doctoral research. International Journal of Doctoral Studies, 13, 9-29. doi.org/10.28945/3941

Piaget, J., \& Wells, P. A. (1972). Psychology and epistemology: Towards a theory of knowledge. London, UK: Allen Lane.

Pritchard, H., \& Gabrys, J. (2016). From citizen sensing to collective monitoring: Working through the perceptive and affective problematics of environmental pollution. GeoHumanities, 2(2), 354-371. doi.org/10.1080/2373566X.2016.1234355

Regalado, C. (2017). Getting out of their way: Do-it-yourselfers, sensing, and self-reliance. In V. Loreto (Ed.), Participatory sensing, opinions and collective awareness (pp. 273-298). Cham, Switzerland: Springer.

Shapiro, N. (2015). Attuning to the chemosphere: Domestic formaldehyde, bodily reasoning, and the chemical sublime. Cultural Anthropology, 30(3), 368-393. doi.org/10.14506/ ca30.3.02

Shove, E. (2003). Comfort, cleanliness and convenience: The social organization of normality. Oxford, UK \& New York, NY: Berg.

Sloterdijk, P. (2016). Foams, spheres volume III: Plural spherology (W. Ho-ban, Trans.). Los Angeles, CA: Semiotext(e).

Steinemann, A., Wargocki, P., \& Rismanchi, B. (2017). Ten questions concerning green buildings and indoor air quality. Building and Environment, 112, 351-358. doi.org/ 10.1016/j.buildenv.2016.11.010

Vilsmaier, U., Brandner, V., \& Engbers, M. (2018). Research in-between: The constitutive role of cultural differences in transdisciplinarity. Journal of Engineering \& Science, 8, 169-179. doi.org/10.22545/2017/00093 
Wakefield-Rann, R., Fam, D., \& Stewart, S. (2018). Routine exposure: Social practices and environmental health risks in the home, Social Theory and Health, 1-18. doi.org/ 10.1057/s41285-018-00084-8

Whatmore, S. (2006). Materialist returns: Practising cultural geography in and for a more-than-human world. Cultural Geographies, 13(4), 600-609. doi.org/10.1191/ $1474474006 \mathrm{cgj} 377 \mathrm{oa}$

Wylie, S., Wilder, E., Vera, L., Thomas, D., \& McLaughlin, M. (2017). Materializing exposure: Developing an indexical method to visualize health hazards related to fossil fuel extraction. Engaging Science, Technology, and Society, 3, 426-463. doi.org/10.17351/ ests2017.123

Yang, T., Xiong, J., Tang, X., \& Misztal, P. K. (2018). Predicting indoor emissions of cyclic volatile methylsiloxanes (cVMS) from the use of personal care products by university students. Environmental Science \& Technology. doi.org/10.1021/acs.est.8b00443

Young, M. D., \& Wilmott, P. (1957). Family and kinship in East London. London, UK: Routledge and Kegan Paul.

Zukin, S. (2009). Changing landscapes of power: Opulence and the urge for authenticity. International Journal of Urban and Regional Research, 33(2), 543-553. doi.org/10.1111/ j.1468-2427.2009.00867.x 
This text is taken from Human Ecology Review, Volume 24, Number 2, 2018, published by ANU Press, The Australian National University, Canberra, Australia. doi.org/10.22459/HER.24.02.2018.01 